\title{
DESAIN SISTEM INFORMASI UNTUK TRACKING DAN TRACING PADA WAREHOUSE DENGAN MENGGUNAKAN TEKNOLOGI QR CODE
}

\author{
Ivan Taufan, Amelia Santoso \\ Magister Teknik Industri Universitas Surabaya \\ Jl. Raya Rungkut, Kali Rungkut, Kec. Rungkut, Kota SBY, Jawa Timur 60293
}

(Received: February 25, 2021/ Accepted: May 19, 2021)

\begin{abstract}
Abstrak
Industrial Revolution 4.0 menyebabkan pelaku supply chain untuk dapat terus beradaptasi dengan teknologi agar tetap kompetitif. Salah satu cara yang dapat digunakan bagi pelaku supply chain adalah dengan menerapkan teknologi IoT untuk membantu memudahkan pelaku supply chain dalam melakukan proses tracking dan tracing inventory. Dengan adanya IoT ini, seluruh pergerakan mulai dari proses penerimaan inventory sampai proses pengeluaran inventory dapat tercatat secara sistem online. Proses tracking dan tracing ini bertujuan untuk membantu mengetahui posisi dari inventory pada warehouse dan memastikan jika inventory dikeluarkan mengikuti aturan FIFO. Desain sistem berbasis IoT ini dibuat dengan menggunakan metode pendekatan System Development Live Cycle (SDLC) sampai pada tahapan desain sistem. Hasil akhir dari studi ini adalah desain sistem informasi yang menggunakan teknologi IoT dan QR code untuk proses tracking dan tracing inventory di dalam warehouse. Dengan adanya sistem informasi ini, jumlah inventory yang kadaluarsa dapat menurun.
\end{abstract}

Kata Kunci: supply chain; tracing; tracking; $Q R$ code

\begin{abstract}
[Information System Design for Tracking and Tracing Using QR Code in Warehouse] Industrial Revolution 4.0 causes supply chain player to continue adapting technology to stay competitive. One way for supply chain player is by implementing Internet of Things (IoT) for tracking dan tracing inventory in supply chain process. With IoT, all inventory movement and activity from inbound area to outbound area can be recorded by system. This tracking and tracing process aim to help determine the position of the inventory in warehouse and ensure the issued inventory is following FIFO rules. This IoT-based system created using System Development Live Cycle (SDLC) approach up to system design step. The result of this study is an information system design that uses IoT and QR code technology for tracking and tracing inventory in warehouse. With this information system, the amount of expired inventory can decrease.
\end{abstract}

Keyword: supply chain; tracing; tracking; QR code

\section{Pendahuluan}

Warehouse selaku pendukung supply chain dituntut untuk bisa bekerja dengan cepat dan akurat agar tetap bisa kompetitif. Salah satu cara yang dapat digunakan untuk meningkatkan kinerja dari warehouse adalah dengan menerapkan teknologi sistem informasi pada warehouse. Camargo (2017) mengatakan bahwa mustahil bagi perusahaan atau pelaku dalam supply chain untuk dapat memiliki supply chain yang efektif tanpa adanya sistem informasi yang baik. Sistem informasi dapat meningkatkan performa dari sebuah perusahaan dan efektifitas dari seluruh rekanan yang ada di dalam supply chain (Camargo dkk., 2017).

PT. XYZ merupakan perusahaan yang memproduksi pakan ternak untuk ayam. Jumlah produk yang disimpan di warehouse PT. XYZ banyak dan beragam yang tersebar pada beberapa warehouse. Saat ini, PT. XYZ sudah memiliki ERP (Enterprise Resource Planning) yang berfungsi untuk membantu proses penghitungan jumlah stok inventory dan penentuan $R e$ order Point (RoP). Proses perhitungan stok ini dihitung dengan cara memasukan jumlah inventory yang diterima pada saat proses penerimaan dan memasukan jumlah inventory lagi ketika inventory tersebut dikeluarkan. Tetapi sistem ERP milik PT. XYZ memiliki kelemahan yaitu tidak mampu membantu membantu melakukan proses tracking dan tracing inventory yang berfungsi untuk memberikan rekomendasi inventory mana yang harus dikeluarkan terlebih dahulu jika mengikuti aturan FIFO (First In First Out). Sistem penentuan pengeluaran inventory yang ada masih menggunakan paperbased yang mencatat lokasi simpan dan tanggal terima dari inventory tersebut. Karena masih menggunakan sistem yang masih paper based, PT. XYZ beberapa kali 
mengeluarkan produk yang tidak sesuai dengan FIFO. Proses pengeluaran yang tidak FIFO ini akan menyebabkan produk-produk yang disimpan ini mengalami kadaluarsa.

Karena itu peranan teknologi sistem informasi sangat penting di sini. Dengan adanya teknologi sistem komunikasi sistem informasi, warehouse dapat menerapkan sistem tracking dan tracing untuk seluruh inventory yang dimiliki. Dengan adanya sistem informasi ini, warehouse dapat mengurangi kesalahan pengeluaran inventory dan menurunkan inventory yang kadaluarsa. Karena itu penelitian ini membuat tentang desain sistem informasi berbasis IoT yang membantu proses tracking dan tracing agar inventory yang dikeluarkan sesuai dengan aturan FIFO.

Era Industrial revolution 4.0 mengenalkan kita dengan IoT (Internet of Things). Definisi dari IoT sangat beragam, tetapi menurut Haddud dkk., (2017), IoT merupakan sebuah cara untuk berkomunikasi dengan beberapa objek dengan menggunakan internet. IoT dapat digunakan sebagai media komunikasi antar individu pada suatu supply chain karena internet memiliki sifat cepat, murah dan efisien (Boiko dkk., 2019). Dapat dikatakan jika era Industrial Revolution 4.0 membawa perubahanperubahan dalam SCM terutama adalah hal information acquisition dan information sharing yang sudah serba otomatis (Barata dkk., 2018). Aliran informasi yang cepat dan akurat dapat membantu mempermudah proses yang ada di dalam supply chain, sehingga perusahaanperusahaan selalu berusaha untuk memperbaharui sistem informasi agar dapat tetap bersaing dengan perusahaan lain yang juga sudah mulai menerapkan sistem informasi (Qrunfleh dan Tarafdar, 2014; Sundram dkk., 2018).

Ben-Daya (2017) mengatakan "IoT merupakan jaringan dari physical object (sensor) yang terhubung secara digital dengan tujuan untuk memonitor dan berinteraksi pada internal perusahaan, antar perusahaan dan pada seluruh jaringan supply chain-nya yang memungkinkan visibilitas, tracking, dan information sharing untuk memfasilitasi timely planning, control, dan koordinasi pada proses supply chain". Salah satu karakteristik dari adanya IoT dalam SCM adalah information sharing (Haddud dkk., 2017). Dengan information sharing ini, IoT dapat membuat SCM terlihat secara utuh dan keseluruhan pada seluruh bagian yang ada di dalam SCM. Dengan kata lain IoT membantu meningkatkan visibilitas dari SCM. Menurut Tsang dkk., (2018), IoT memiliki 4 layer, yaitu: sensing layer (barcode, RFID, NFC), gateway/ network layer (Internet), management service layer (Cloud/ database), dan application layer.

Information System (IS) pada umumnya digunakan untuk membantu proses transparansi yang ada pada supply chain. (Qrunfleh dan Tarafdar, 2014; Camargo dkk., 2017). Dengan adanya IS, proses komunikasi antar individu dalam supply chain dapat dilakukan dengan mudah dan cepat, sehingga memberikan efek berkurangnya lead time pada supply chain (Sundram dkk., 2018). Aliran informasi yang lancar juga akan meningkatkan performa dari supply chain (Bo, 2009).

Penelitian Shamsuzzoha dan Helo (2011) menyatakan pentingnya tracking dan tracing untuk logistik dalam supply chain. Pada penelitian tersebut, mereka merancang sebuah sistem untuk mengetahui posisi pergerakan inventory dalam supply chain. Proses tracking dan tracing ini dilakukan dengan mendaftarkan inventory ke dalam sistem dan menghasilkan sebuah identitas unik untuk inventory tersebut. Identitas tersebut akan selalu didaftarkan ulang setiap kali ada perpindahan inventory.

Fan dkk., (2015) dan Muyumba dan Phiri (2017) merancang sebuah sistem IoT yang mirip dengan penelitian Shamsuzzoha dan Helo (2011), tetapi menggunakan teknologi RFID dan dalam skala yang lebih kecil. Sistem ini digunakan untuk melacak posisi inventory pada sebuah gudang. Sistem ini membantu mempermudah user yang bekerja di dalam gudang tersebut dalam melakukan pemilihan inventory agar tidak terjadi kesalahan pada saat proses pengambilan. Sistem yang dibuat ini cocok untuk produk yang tidak memiliki jangka kadaluarsa atau memiliki kadaluarsa yang panjang. Hal ini disebabkan karena sistem yang dibuat digunakan untuk membantu pelacakan posisi barang pada gudang. Sistem tidak membantu user dalam menentukan inventory mana yang harus dikeluarkan terlebih dahulu jika mengikuti aturan FIFO. Untuk produk dengan masa kadaluarsa yang pendek, hal ini menjadi masalah karena dapat menimbulkan inventory yang kadaluarsa ketika dikeluarkan.

Sembiring dkk., (2019) membuat sebuah sistem berbasis web untuk membantu perusahaan dalam menentukan raw material yang harus dikeluarkan menurut aturan FIFO. User harus mendaftarkan terlebih dahulu dengan memasukkan sebuah kode unik ke dalam sistem dan akan disimpan oleh sistem. Proses pengeluaran juga dilakukan dengan mengetikan kode ke dalam sistem untuk melakukan pemotongan stok. Kelemahan dari sistem ini adalah sistem tidak memberikan lokasi pasti dari inventory pada gudang. Hal ini tidak cocok jika jumlah dan ukuran gudang yang digunakan banyak karena proses pencarian memerlukan waktu bagi user.

Penelitian-penelitian sebelumnya sudah mempertimbangkan kebutuhan IS pada warehouse, tetapi penelitian di atas tersebut masih belum membahas mengenai sistem berbasis IoT untuk membantu mengeluarkan inventory secara FIFO. IS pada penelitian sebelumnya lebih banyak digunakan untuk melacak posisi dari inventory baik pada warehouse atau pada supply chain. Sedangkan kebutuhan sistem pada PT. XYZ tidak hanya untuk tracking dan tracing posisi inventory, tetapi juga memberikan rekomendasi untuk inventory yang harus diambil sesuai FIFO. Hal ini dikarenakan inventory yang disimpan pada warehouse PT. XYZ memiliki jangka kadaluarsa yang singkat.

Oleh karena itu dalam penelitian ini dikembangkan sebuah sistem yang membantu proses tracking dan tracing inventory yang berbasis IoT untuk 


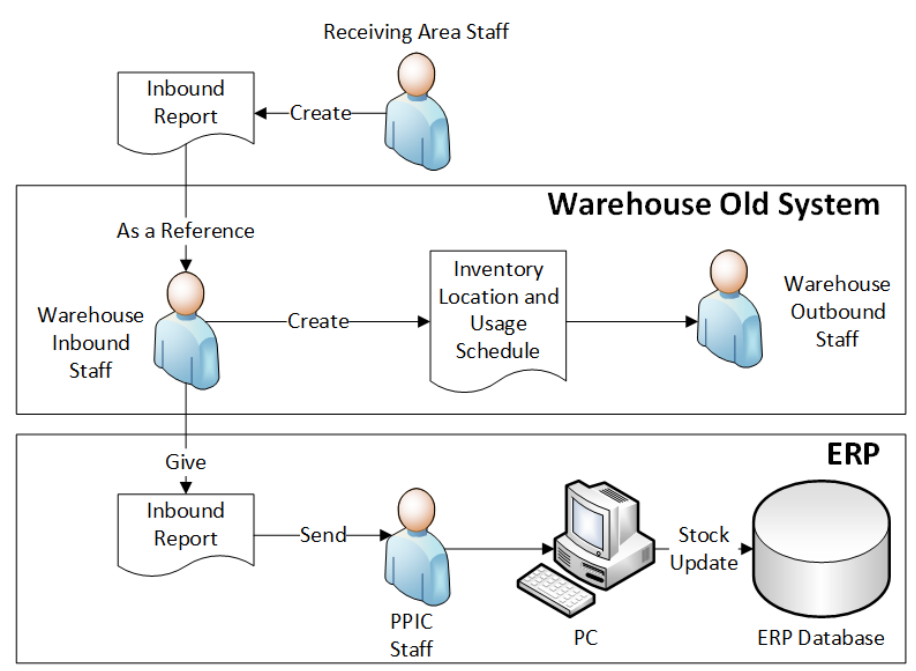

Gambar 1. Hasil Pengamatan Proses Penerimaan Inventory

membantu proses pemilihan dan pengeluaran inventory sesuai FIFO.

\section{Metode Penelitian}

Metode peneletian yang digunakan pada penelitian ini mengacu pada System Development Live Cycle (SDLC) milik Satzinger dkk., (2012), tetapi hanya sampai pada tahapan desain sistem. Tahapan awal pada SDLC yang dilakukan adalah requirement analysis yang berfungsi untuk mengidentifikasi masalah dan dilanjutkan dengan penjabaran fungsi-fungsi dari sistem yang menyelesaikan masalah tersebut. Tahapan SDLC berikutnya adalah design yang bertujuan untuk mulai merancang sistem yang dibuat. Tahapan desain ini menggunakan metode object-oriented programming (Britton dan Doake, 2005). Langkah-langkah untuk desain menggunakan Object-oriented programing (OOP) adalah membuat use case diagram, class diagram, dan system sequence diagram (SSD).

\section{Hasil dan Pembahasan Analisa Kebutuhan}

Pada SDLC, langkah awal yang diperlukan sebelum membangun sistem adalah melakukan analisa kebutuhan. Analisa kebutuhan berfungsi untuk menjelaskan alasan kenapa sistem ini diperlukan dan apa saja fungsi dari sistem informasi yang akan dibuat. Tahap awal pada analisa kebutuhan adalah melakukan pengamatan terhadap kondisi warehouse. Proses penerimaan inventory dapat dilihat pada Gambar 1 dapat dilihat staff warehouse menerima laporan inbound dari bagian penerimaan yang berisikan nama inventory, kode inventory dan tanggal terima inventory. Oleh staff warehouse akan dibuatkan laporan penyimpanan yang berisikan kode inventory, lokasi simpan inventory, dan tanggal terima inventory. Dokumen laporan penyimpanan ini biasa disebut dengan lokasi simpan dan jadwal pemakaian. Dokumen laporan penyimpanan ini akan diteruskan ke staff warehouse yang bertugas untuk mengeluarkan inventory. Laporan inbound diteruskan ke PPIC (Production Planner and Inventory Control) untuk

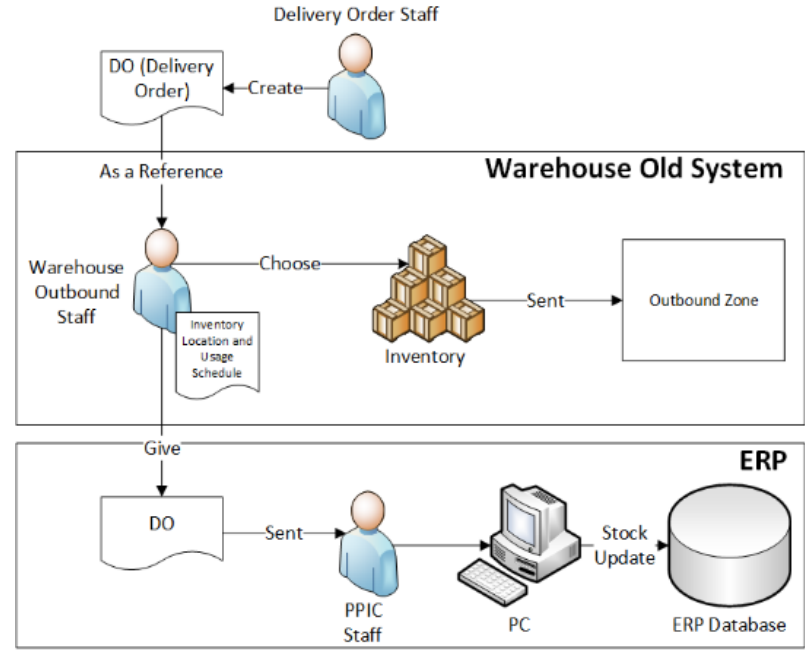

Gambar 2. Hasil Pengamatan Proses Pengeluaran Inventory

digunakan sebagai acuan dalam update stok pada sistem ERP yang digunakan.

Gambar 2 merupakan proses pengeluaran inventory pada warehouse. Staff warehouse yang bertugas mengeluarkan akan menerima dokumen DO (Delivery Order) yang berisikan nama-nama inventory yang dipesan oleh customer. Staff warehouse harus melakukan pemilihan inventory berdasarkan laporan penyimpanan yang dibuat oleh staff warehouse yang bertugas melakukan penyimpanan. Bagian pengeluaran harus menentukan inventory mana yang harus dikeluarkan terlebih dahulu mengikuti aturan FIFO. Ketika inventory sudah dipilih, staff warehouse harus memastikan jika inventory yang diletakkan pada area muat sudah benar sesuai dengan DO. Inventory akan dimuat jika inventory sudah sesuai dengan DO. Dokumen DO akan diteruskan ke staff PPIC untuk digunakan sebagai acuan dalam update jumlah stok pada sistem ERP yang ada.

Dari hasil pengamatan di atas, timbul masalah utama yaitu inventory yang dikeluarkan tidak sesuai dengan FIFO. Hal ini menyebabkan inventory yang disimpan mengalami kadaluarsa. Daftar identifikasi masalah untuk inventory yang dikeluarkan tidak sesuai dengan FIFO dapat dilihat pada Tabel 1. Dari hasil identifikasi masalah tersebut, dapat dibuat alternatif perbaikan yang dilakukan oleh sistem. Daftar alternatif perbaikan yang dilakukan oleh sistem dapat dilihat pada

Tabel 2.

Fungsi-fungsi yang diharapkan pada sistem dapat terlihat dari hasil identifikasi masalah dan alternatif perbaikan. Langkah akhir dari analisa kebutuhan adalah membuat rancangan akhir dari sistem usulan. Desain ini bertujuan untuk memberikan gambaran bagainama sistem usulan ini diterapkan pada lapangan dan digunakan bersamaan dengan sistem ERP yang sudah ada.

Desain akhir sistem dapat dilihat pada Gambar 3 dan Gambar 4. Gambar 3 merupakan desain rancangan akhir yang digunakan oleh inbound staff dalam proses penerimaan barang. Sistem dapat diakses melalui apikasi pada smartphone android. Setiap kali inbound staff 
Tabel 1. Identifikasi Masalah untuk Inventory Dikeluarkan Tidak Sesuai dengan Aturan FIFO

\begin{tabular}{|c|c|c|}
\hline No & Kategori & Penyebab \\
\hline 1 & Machine & $\begin{array}{l}\text { 1.1. Tidak ada catatan aktifitas warehouse } \\
\text { 1.2. Sistem yang ada hanya untuk menghitung stok (ERP) }\end{array}$ \\
\hline 2 & Man & $\begin{array}{l}\text { 2.1. Salah baca dokumen karena terburu-buru menentukan } \\
\text { 2.2. Salah pada saat proses pembuatan dokumen }\end{array}$ \\
\hline 3 & Method & $\begin{array}{l}\text { 3.1. Proses pembuatan dokumen secara manual } \\
\text { 3.2. Proses pemilihan inventory yang hanya berdasarkan dokumen } \\
\text { 3.3. Proses pembacaan dokumen secara manual } \\
\text { 3.4. Proses verifikasi untuk pengeluaran akhir secara manual }\end{array}$ \\
\hline
\end{tabular}

Tabel 2. Alternatif Perbaikan

\begin{tabular}{|c|c|c|}
\hline No & Identifikasi Masalah & Alternatif Perbaikan \\
\hline 1 & $\begin{array}{l}\text { Sistem yang sudah ada hanya untuk menghitung Stok } \\
\text { (ERP) }\end{array}$ & Sistem yang membantu ERP dalam penentuan FIFO \\
\hline 2 & Tidak ada catatan aktifitas pada warehouse & Sistem yang mencatat secara digital aktifitas warehouse \\
\hline 3 & Proses pembuatan dokumen yang masih manual & Sistem yang mendaftarkan inventory secara otomatis \\
\hline 4 & $\begin{array}{l}\text { Proses pemilihan inventory yang hanya berdasarkan } \\
\text { dokumen tertulis }\end{array}$ & $\begin{array}{l}\text { Sistem yang memberikan rekomendasi inventory yang } \\
\text { dikeluarkan }\end{array}$ \\
\hline 5 & Proses pembacaan dokumen yang terburu-buru & Sistem yang membantu menentukan inventory secara langsung \\
\hline 6 & Proses verifikasi akhir dilakukan secara manual & Sistem yang membantu proses verifikasi \\
\hline 7 & Kesalahan pada saat pembuatan dokumen & $\begin{array}{l}\text { Sebuah sistem yang dapat langsung membantu proses } \\
\text { pencatatan inventory }\end{array}$ \\
\hline
\end{tabular}

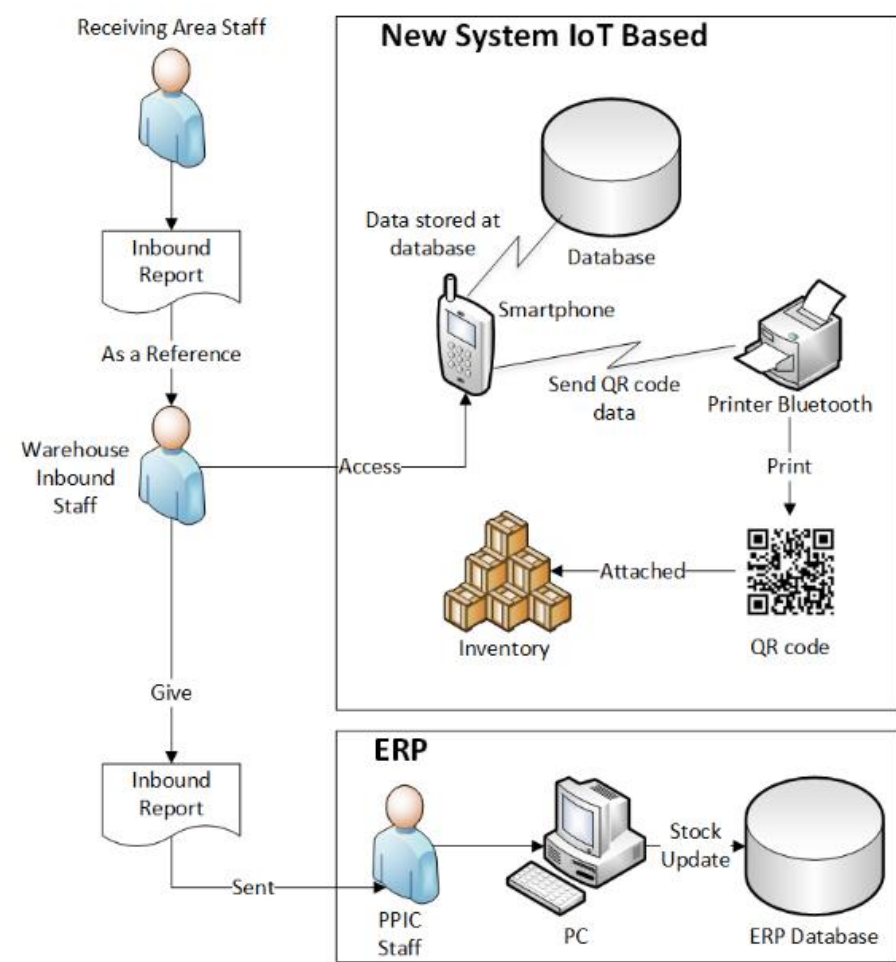

Gambar 3. Desain Akhir Sistem untuk Proses Penerimaan

mendaftarkan inventory ke sistem, database akan melakukan pencatatan seperti nama inbound staff, tanggal, lokasi simpan, dan kode dari inventory tersebut. Data yang sudah tersimpan tadi, akan secara otomatis dibuatkan kode QR yang unik oleh sistem. Kode QR tersebut dapat dicetak oleh inbound staff ke Bluetooth printer untuk mencetak kode QR secara fisik. Kode QR yang sudah dicetak tadi ditempelkan pada inventory yang bersangkutan. Untuk desain rancangan akhir yang

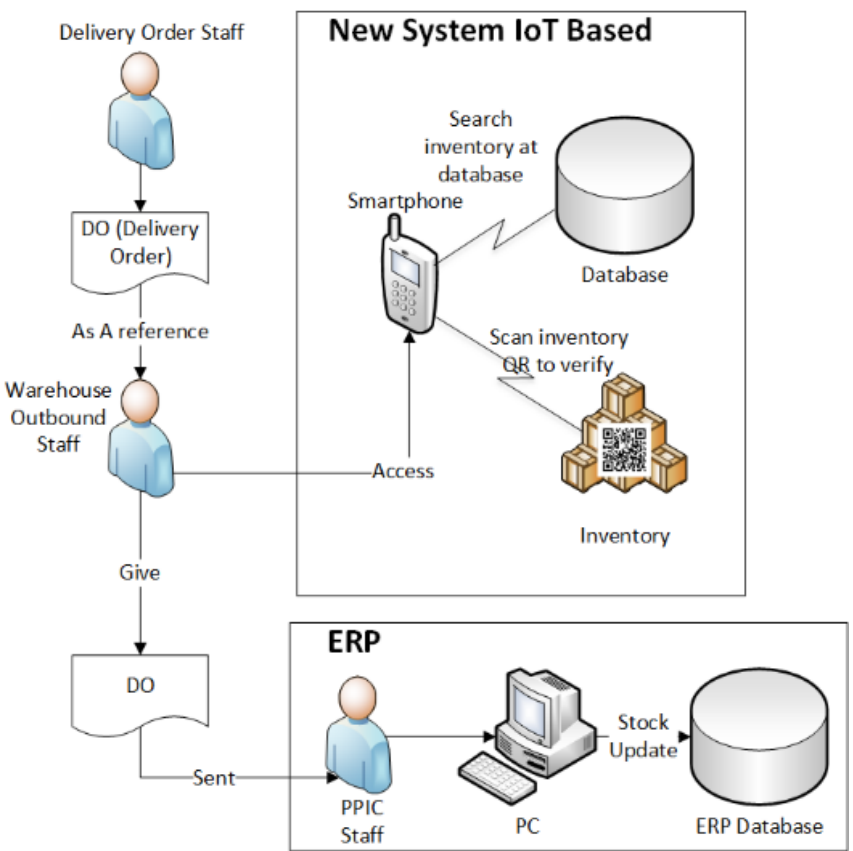

Gambar 4. Desain Akhir Sistem untuk Proses Pengeluaran

digunakan oleh outbound staff dapat dilihat pada Gambar 4. Secara sistem, kode QR ini menjadi identitas dari inventory seperti tanggal penerimaan dan lokasi simpan dari inventory. Identitas ini yang digunakan untuk membantu outbound staff dalam melakukan proses tracking dan tracing inventory.

Outbound staff harus mencari terlebih dahulu inventory yang ingin dikeluarkan dengan mengetikan kode inventory pada sistem. Sistem akan mencari daftar 


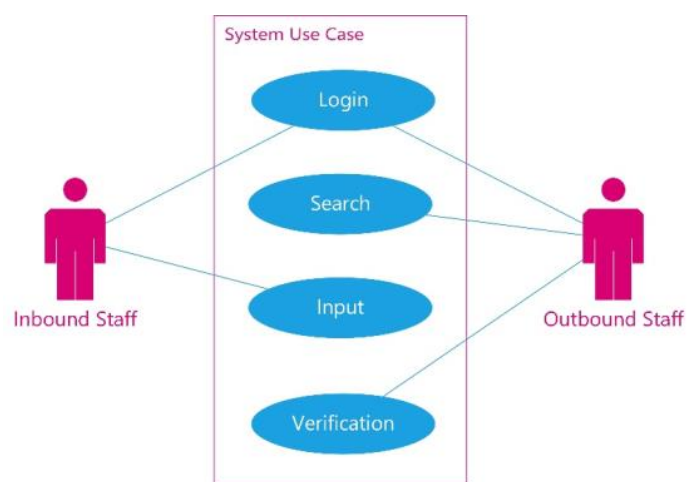

Gambar 5. Use Case Diagram

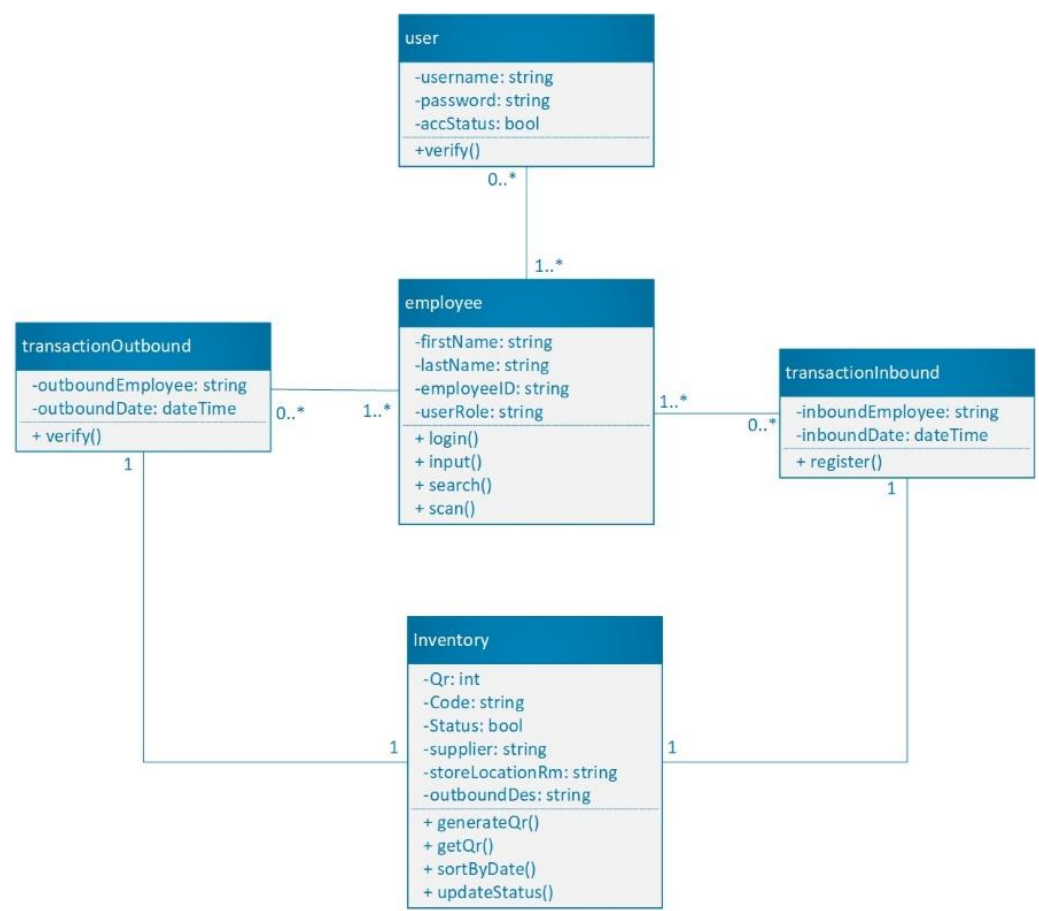

Gambar 6. Class Diagram dari kode inventory yang diketikan oleh outbound staff dan ditampilkan ke outbound staff dengan kondisi inventory sudah diurutkan dengan prioritas inventory terlama untuk dikeluarkan terlebih dahulu. Outbound staff akan memilih inventory yang sudah ditampilkan oleh sistem dan sistem akan memberikan informasi lokasi simpan dari inventory yang sudah dipilih. Ketika inventory yang dipilih tadi sudah datang ke area muat, outbound staff akan melakukan scan pada kode QR yang terpasang pada inventory sebagai proses verifikasi. Setelah proses verifikasi berhasil, sistem akan merubah status inventory tersebut dari belum keluar menjadi sudah keluar.

\section{Desain Sistem}

Dari analisa kebutuhan, dilanjutkan dengan tahapan desain sistem. Pada penelitian ini, jenis desain sistem yang digunakan adalah object oriented programming (OOP) (Britton dan Doake, 2005). Tahap ini terdiri dari proses pembuatan use case diagram, system sequence diagram (SSD), dan class diagram.

\section{a. Use Case Diagram}

Use case diagram merupakan gambaran besar dari sistem. Pada Gambar 5 dapat terlihat ada 2 aktor yaitu inbound staff yang bertugas untuk mendaftarkan inventory ke dalam sistem dan menentukan lokasi simpan dari inventory dan outbound staff yang bertugas untuk memilih inventory yang akan dikeluarkan dan melakukan proses verifikasi akhir sebelum dimuat. Di dalam use case diagram terdapat 4 macam use casel aktifitas yang dilakukan oleh actor. Inbound staff dapat melakukan aktifitas login dan input inventory. Outbound staff dapat melakukan aktifitas login, search inventory, dan verification untuk proses pengeluaran inventory.

\section{b. Class Diagram}

Dari use case diagram, dapat dikembangkan dengan membuat class diagram untuk membantu menjelaskan apa saja attribute dan method yang dimiliki oleh setiap class. Class diagram membantu menjelaskan relasi antara objek yang ada di dalam sistem. Gambar dari class diagram dapat dilihat pada Gambar 6.

\section{c. System Sequence Diagram}

Dari class diagram tersebut, dibuat system sequence diagram (SSD) untuk membantu menjelaskan cara kerja dari sistem dengan memberikan gambaran aksi dan reaksi dari sistem ketika mendapat perintah dari user. Untuk sequence diagram milik inbound staff dapat dilihat pada Gambar 7 dan sequence diagram untuk outbound staff dapat dilihat pada Gambar .

\section{Analisis Desain Usulan}

Langkah selanjutnya dari penelitian ini adalah membuat perbandingan antara sistem usulan dengan sistem yang sudah ada. Gambar 3 dan Gambar $\mathbf{4}$ dapat terlihat keuntungan dari sistem baru. Daftar keuntungan dari sistem baru ini dapat dilihat pada Tabel 3. Jika sistem ERP yang sudah saat ini hanya dapat digunakan untuk menghitung jumlah stok dan menentukan RoP, maka dengan adanya tambahan sistem yang baru ini dapat menutupi kelemahan dari sistem ERP yang sudah ada dengan menambahkan fitur pemberian rekomendasi pengeluaran inventory berdasarkan FIFO dan pencatatan riwayat aktifitas di warehouse.

Kelemahan dari sistem usulan adalah sistem ini tidak dapat terintegrasi dengan ERP yang sudah ada. Hal ini membuat pihak PPIC masih tetap perlu mengakses ERP lagi walau inventory sudah didaftarkan oleh pihak warehouse melalui sistem baru, sehingga rawan muncul 


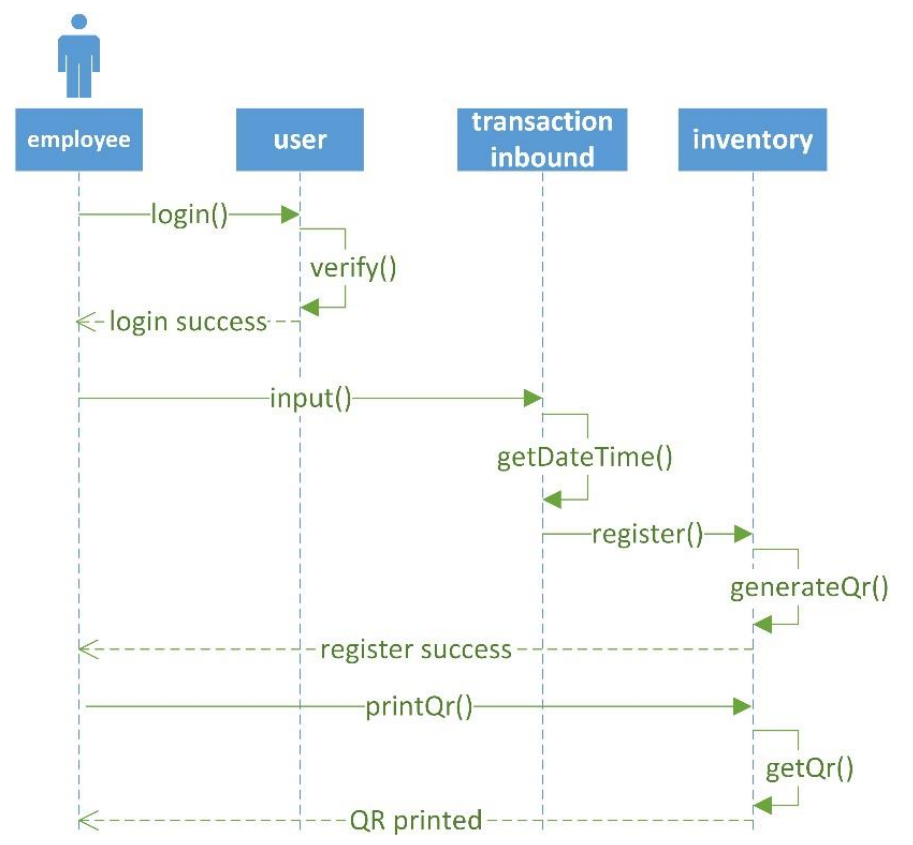

Gambar 7. System Sequence Diagram untuk Proses Penerimaan

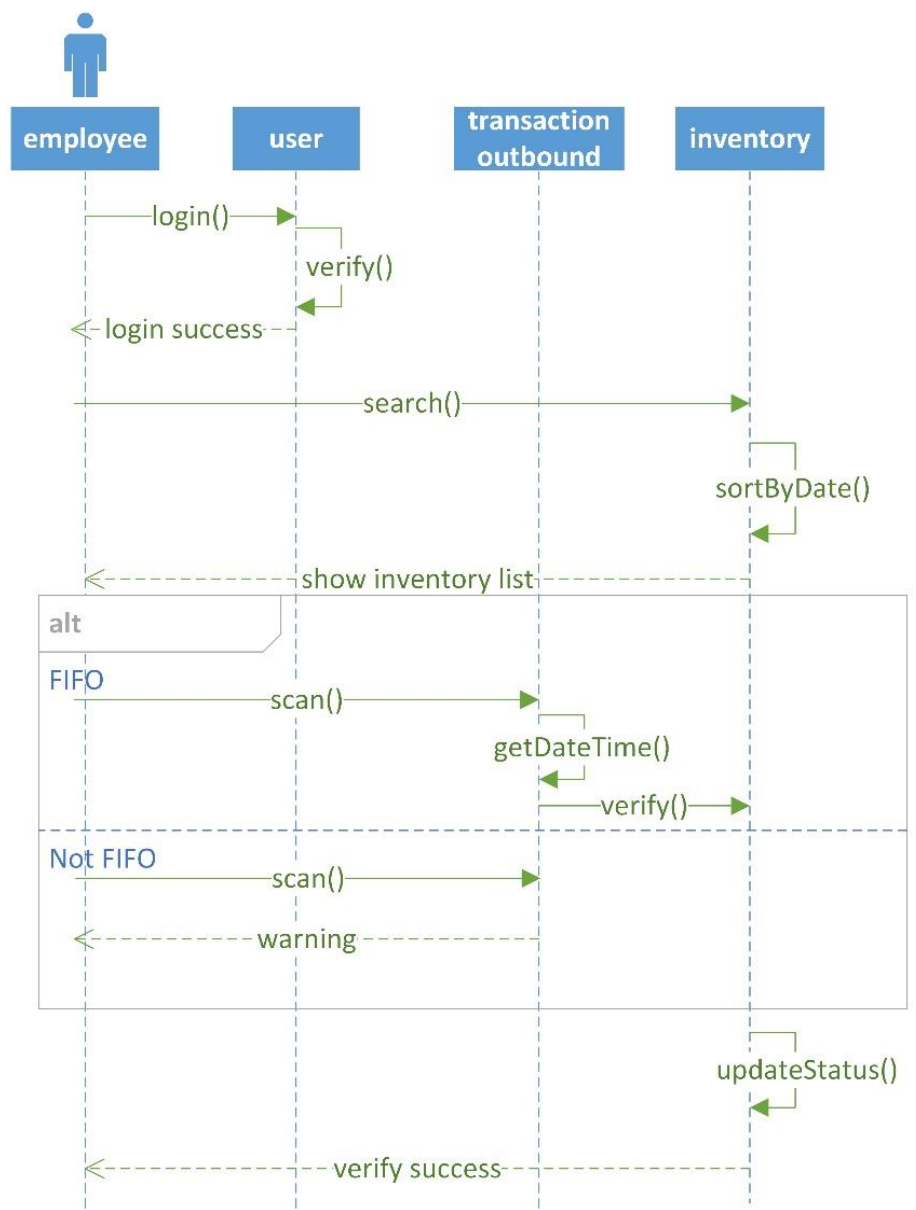

Gambar 8. System Sequence Diagram untuk Proses Pengeluaran

Tabel 3. Perbandingan Kondisi Saat ini dengan Kondisi setelah Penerapan Sistem

\begin{tabular}{|c|c|c|c|}
\hline \multicolumn{2}{|r|}{ Kondisi Saat Ini } & \multicolumn{2}{|r|}{ Kondisi setelah Penerapan Sistem } \\
\hline & Fungsinya: & ERP & $\begin{array}{l}\text { Fungsinya: } \\
\text { Pengecekan Stok } \\
\text { Penentuan Re-order Point }\end{array}$ \\
\hline ERP & $\begin{array}{l}\text { Pengecekan Stok } \\
\text { Penentuan Re-order Point } \\
\text { (RoP) }\end{array}$ & $\begin{array}{l}\text { Sistem } \\
\text { Tambahan }\end{array}$ & $\begin{array}{l}\text { Fungsinya: } \\
\text { Memberikan rekomendasi untuk proses } \\
\text { pengeluaran RM dan FG berdasarkan FIFO. } \\
\text { Mencatat Riwayat aktifitas pada warehouse RM } \\
\text { dan FG }\end{array}$ \\
\hline
\end{tabular}

perbedaan data ketika ada kesalahan pada saat proses input.

\section{Kesimpulan}

Hasil penelitian ini berupa sebuah desain sistem informasi berbasis IoT dan berfungsi untuk membantu mengurangi inventory yang kadaluarsa pada warehouse. Desain sistem ini terdiri dari: use case diagram, class diagram, dan system sequence diagram. Untuk mengimplementasikan desain ini, use case diagram, class diagram, dan system sequence diagram diserahkan kepada programmer atau software engineer untuk dibuatkan aplikasi dari sistem informasi berbasis IoT.

Sistem yang dibangun ini memiliki kelemahan yaitu, sistem ERP yang sudah ada masih belum terintegrasi dengan sistem informasi berbasis IoT. Data yang tersimpan pada ERP bisa jadi terdapat perbedaan dengan sistem informasi yang dibuat karena terdapat dua kali proses input oleh dua department yang berbeda, satu oleh PPIC dan satu oleh warehouse. Oleh karena itu untuk penelitian selajutnya adalah mengintegrasikan sistem ERP yang sudah ada dengan sistem yang dibangun. Hal ini bertujuan untuk mencegah terjadinya perbedaan data antara ERP dengan sistem informasi yang dibuat.

\section{Daftar Pustaka}

Barata, J., Rupino, P., \& Stal, J. (2018). Mobile supply chain management in the Industry 4.0 era: An annotated bibliography and guide for future 
research. Journal of Enterprise Information Management, 31(1), 173-192.

Ben-Daya, M., Hassini, E., \& Bahroun, Z. (2017). Internet of things and supply chain management: a literature review. International Journal of Production Research, 7543(November), 1-24.

Bo, Y., \& Guangwen, H. (2009). Supply chain information transmission based on RFID and internet of things. 2009 Second ISECS International Colloquium on Computing, Communication, Control, and Management, CCCM 2009, 4, 166-169.

Boiko, A., Shendryk, V., \& Boiko, O. (2019). Information systems for supply chain management: Uncertainties, risks and cyber security. Procedia Computer Science, 149, 65-70.

Britton, C., \& Doake, J. (2005). A Student Guide to Object-Oriented Development (1st ed.).

Camargo, P. De, José, C., \& Jabbour, C. (2017). International Journal of Information Management Information systems and sustainable supply chain management towards a more sustainable society: Where we are and where we are going. International Journal of Information Management, 37(4), 241-249.

Fan, T., Tao, F., Deng, S., \& Li, S. (2015). Impact of RFID technology on supply chain decisions with inventory inaccuracies. International Journal of Production Economics, 159, 117-125.

Haddud, A., DeSouza, A., Khare, A., \& Lee, H. (2017). Examining potential benefits and challenges associated with the Internet of Things integration in supply chains. Journal of Manufacturing Technology Management, 28(8), 1055-1085.

John W, S. ; Robert B, jackson;, \& Stephern D, B.
(2012). Systems Analysis And Design In A Changing World.

Muyumba, T., \& Phiri, J. (2017). A Web based Inventory Control System using Cloud Architecture and Barcode Technology for Zambia Air Force. International Journal of Advanced Computer Science and Applications, 8(11), 132-142.

Qrunfleh, S., \& Tarafdar, M. (2014). Supply chain information systems strategy: Impacts on supply chain performance and firm performance. International Journal of Production Economics, 147(PART B), 340-350.

Sembiring, A. C., Tampubolon, J., Sitanggang, D., Turnip, M., \& Subash. (2019). Improvement of Inventory System Using First in First Out (FIFO) Method. Journal of Physics: Conference Series, 1361(1).

Shamsuzzoha, A., \& Helo, P. (2011). Real-time tracking and tracing system: Potentials for the logistics network. ... of the 2011 International Conference on ..., 242-250.

Sundram, V. P. K., Bahrin, A. S., Abdul Munir, Z. B., \& Zolait, A. H. (2018). The effect of supply chain information management and information system infrastructure: The mediating role of supply chain integration towards manufacturing performance in Malaysia. Journal of Enterprise Information Management, 31(5), 751-770.

Tsang, Y. P., Choy, K. L., Wu, C. H., Ho, G. T. S., Lam, C. H. Y., \& Koo, P. S. (2018). An Internet of Things (IoT)-based risk monitoring system for managing cold supply chain risks. Industrial Management and Data Systems, 118(7), 14321462. 